EPJ Web of Conferences 33, 01006 (2012)

DOI: $10.1051 /$ epjconf/20123301006

(C) Owned by the authors, published by EDP Sciences, 2012

\title{
Analysing the role of fusion power in the future global energy system
}

\author{
H. Cabal ${ }^{1, \text { a }}$, Y. Lechón ${ }^{1}$, U.Ciorba ${ }^{2}$, F.Gracceva ${ }^{2}$, T.Eder ${ }^{3}$, T.Hamacher ${ }^{3}$, A.Lehtila ${ }^{4}$, \\ M.Biberacher ${ }^{5}$, P.E.Grohnheit ${ }^{6}$, D.Ward ${ }^{7}$, W.Han ${ }^{7}$, C.Eherer ${ }^{8}$ and A.Pina ${ }^{9}$
}

${ }^{1}$ CIEMAT, Av.Complutense, 40. 28040 Madrid. Spain

${ }^{2}$ ENEA, Lungotevere Thaon di Revel, 76. 00196 Rome. Italy

${ }^{3}$ Max-Planck-IPP, Boltzmannstraße 2. 85748 Garching. Germany

${ }^{4}$ VTT, Vuorimiehentie 5. 02044 Espoo. Finland

${ }^{5}$ ÖAW, Dr. Ignaz Seipel-Platz 2. 1010 Vienna. Austria

${ }^{6}$ DTU, Frederiksborgvej 399. 4000 Roskilde. Denmark

${ }^{7}$ UKAEA, Abingdon, OX14 3DB, Oxfordshire, U.K.

${ }^{8}$ EDFA-Garching, Boltzmannstraße 2. 85748 Garching. Germany

${ }^{9}$ IST, Av. Rovisco Pais, 1. 1049-001 Lisboa. Portugal

\begin{abstract}
This work presents the EFDA Times model (ETM), developed within the European Fusion Development Agreement (EFDA). ETM is an optimization global energy model which aims at providing the optimum energy system composition in terms of social wealth and sustainability including fusion as an alternative technology in the long term. Two framework scenarios are defined: a Base case scenario with no limits to $\mathrm{CO}_{2}$ emissions, and a $450 \mathrm{ppm}$ scenario with a limit of $450 \mathrm{ppm}$ in $\mathrm{CO}_{2}$-eq concentrations set by 2100 . Previous results showed that in the Base case scenario, with no measures for $\mathrm{CO}_{2}$ emission reductions, fusion does not enter the energy system. However, when $\mathrm{CO}_{2}$ emission restrictions are imposed, the global energy system composition changes completely. In a 450ppm scenario, coal technologies disappear in a few decades, being mainly replaced by nuclear fission technologies which experience a great increase when constrained only by Uranium resources exhaustion. Fission technologies are then replaced by the fusion power plants that start in 2070, with a significant contribution to the global electricity production by 2100 . To conclude the work, a sensitivity analysis will be presented on some parameters that may affect the possible role of fusion in the future global energy system.
\end{abstract}

\section{Introduction}

In a global energy system threaten by climate change, depletion of conventional energy resources, increasing instability in historical energy regions, and a continuing demand growth, nuclear fusion

\footnotetext{
a e-mail : helena.cabal@ciemat.es
}

This is an Open Access article distributed under the terms of the Creative Commons Attribution License 2.0, which permits unrestricted use, distribution, and reproduction in any medium, provided the original work is properly cited. 
comes out as an alternative technology with a potential role in the future global sustainable energy system.

In order to analyse this potential role, a long term prospective analysis has to be performed because fusion is not expected to be available before 2050, thus its impact has to be discussed in a temporal horizon up to 2100 . The only way to approach such long time horizons is by using scenarios, that is, pictures of the future which are consistent within their assumptions but which do not claim to be the most likely development. Through scenarios, the impact of different measures, policies, new technologies, fuels scarcity, and other many energy-related issues, can be explored.

Models provide quantitative results to the chosen scenarios, and are a good tool for the comparison of different measures and policies, and for the elaboration of recommendations for long term energy prospective.

\section{The EFDA Times model}

The EFDA TIMES energy model (ETM) is a global long term partial equilibrium model of the World energy system, which covers the whole system from mining, transport and transformation of primary commodities to final consumption technologies.

It uses the integrated MARKAL-EFOM system (TIMES) [1-3] provided by IEA-ETSAP (Energy Technology Systems Analysis Programme). Similar global multi-regional MARKAL-TIMES models have been used for the preparation of other important long term energy technology evaluation studies. The main difference between ETM and these models lies in the detailed representation of the complete fusion cycle in the model, from Lithium extraction to electricity generation in the fusion power plants. Besides, other technologies are also described with high degree of detail such as nuclear fission and concentrating solar power with energy storage.

The model dynamics is determined by a maximization of total economic surplus which can be considered equivalent to the minimization of overall costs when demands are not price elastic. Furthermore, energy markets in the model are assumed to be competitive and economic agents to have perfect information and perfect foresight, optimizing their decisions along the entire time horizon. The maximization of the objective function is carried out by the TIMES model generator.

The EFDA TIMES model covers a time horizon from 2000 to 2100 divided into periods. Results are given for six different time slices: three seasons (winter, summer, and intermediate) and day/night. With this time division, the differences in energy demand and supply depending on the time of the year, and the day and night, are considered.

The reference energy system includes five energy consumption sectors: residential, commercial, agriculture, industrial and transportation; and two energy supply sectors: electricity and heat production, and upstream/downstream. At the same time the industry sector is divided into 6 energy intensive subsectors: Iron and Steel; Non-Ferrous Metals; Chemical and Petrochemical; Manufacture of other non-metallic minerals; Pulp, paper, and printing of paper products; and all other industrial sectors.

Like any other model of the TIMES family, ETM is said to be technology-rich because it consists of a broad database of thousand present and future potential energy technologies for both, the demand and the supply sectors. Those technologies are well characterized by a number of parameters that can be classified as technical (efficiency, availability, technical lifetime, installed capacity); environmental (emission factors for the main pollutants $\mathrm{CO} 2, \mathrm{CH} 4, \mathrm{~N} 2 \mathrm{O}, \mathrm{SOx}$ ); and economic (investment costs, $\mathrm{O} \& \mathrm{M}$ costs).

The model is driven by energy service demands in each sector. Those demands are computed from a set of demand drivers (population, GDP, number of households) obtained from a general equilibrium model. In this work GEM-E3 [4-5] model has been used to produce the demand drivers in the Base cases and Gtap [6] general equilibrium model to produce the drivers in the high growth development (HG) scenarios for the sensitivity analysis.

There are 15 world regions represented in ETM: Africa, Australia-New Zealand, Canada, China, Central and South America, Eastern Europe, Former Soviet Union, India, Japan, Middle East, 
Mexico, Other Developing Asia, South Korea, United States, and Western Europe. Those regions are connected among them by inter-regional exchange processes (trade of commodities).

\subsection{Heat transmission grids}

Heat transmission grids have been included in ETM following an innovative approach. Heat production by CHP plants has been considered as a virtual heat pump meaning that part of the electricity generated in condensing mode is converted into heat at an efficiency factor that is the inverse of the power-loss ratio. Instead of operating a physical heat pump by electricity, part of the steam in the turbine is sent to a heat exchanger and the district heating network rather than the lowpressure turbine and the power generator.

Interpreting CHP as virtual heat pumps makes it much easier to integrate CHP and heat supply from power stations with CCS into a heat market, where also individual heat pumps become increasingly important. The various heat supply technologies will compete on efficiencies, fuel price and requirement for investment in house installation as well as city-wide infrastructure.

\subsection{The nuclear fuel cycle}

The implementation of the nuclear fuel cycle provides a technology rich representation of the current global nuclear sector and selected future fission technology pathways. This embraces the whole chain of processes from mining, milling and conversion of natural Uranium over enrichment up to fuel production and parts of the reprocessing steps. Additionally, Uranium and Plutonium from the decommissioning of nuclear weapons are implemented as fuelling resources.

Seven different reactor technologies are implemented into the ETM model to facilitate the generation of scenario analysis comparing different technological development pathways in a sense of most reasonable combinations. The technologies representing the back-end of the cycle offer options for direct disposal of spent fuel (e.g. to represent a once through cycle) and range of reprocessing technologies to represent various reprocessing strategies up to closed fuel cycles.

\subsection{Renewable and storage options}

The ETM technological database has been enriched with new Concentrating Solar Power (CSP) technologies with thermal storage facilities. There are two commercial kinds of CSP with storage nowadays: central tower and cylindrical-parabolic trough collectors, with different storage capacities. Updated information on commercial CSP plants with storage has been gathered and new processes have been built to include the different storage options in the solar thermal facilities into the model.

As concentrating solar power plants can not be built in all the regions of the model, suitable areas for solar thermal facilities have been identified for the whole World using GIS tools. First, only areas with direct normal irradiance above $1,800 \mathrm{kWh} / \mathrm{m}^{2}$ have been extracted. Further to this limitation, other areas such as protected areas and areas with slope higher than $2.1 \%$ were excluded. From the remaining areas, only areas classified as bare and sparsely vegetated areas (CORINE, GLC 2000) were considered to be suitable for the installation of this type of plants.

Moreover, availability factors are also dependent on the location of the CSP power plants as well as on the season of the year. These availability factors have been calculated for the suitable areas in each region, season, and time slice for a CSP plant with no storage. In order to estimate the availability factors of the CSP technologies that incorporate energy storage, the availability increase that would result of having the additional storage hours in each case has been added to the seasonal availability factor without storage.

\subsection{Fusion in the model}


Global Lithium resources are estimated in $12 \mathrm{Mt}\left(2.4 \times 10^{8} \mathrm{PJ}\right)$ and extraction and enrichment costs in $4.5 \times 10^{-3} \mathrm{M} \$ / \mathrm{PJ}$. Mined Lithium is transformed into fuel and used in two types of fusion power plant whose characteristics are shown in the next table:

Table 1. Fusion data. Source : [7]

\begin{tabular}{|l|l|l|l|c|c|}
\hline & \multicolumn{1}{|c|}{ Start } & Efficiency & INV & FIXOM & VAROM \\
\hline Basic plant & 2050 & $42 \%$ & $3940 \$ / \mathrm{kW}$ & $65.8 \$ / \mathrm{kWa}$ & $2.16 \mathrm{M} \$ / \mathrm{PJ}$ \\
& 2060 & $42 \%$ & $2950 \$ / \mathrm{kW}$ & $65.8 \$ / \mathrm{kWa}$ & $1.64 \mathrm{M} \$ / \mathrm{PJ}$ \\
\hline Advanced plant & 2070 & $60 \%$ & $2820 \$ / \mathrm{kW}$ & $65.3 \$ / \mathrm{kWa}$ & $2.14 \mathrm{M} \$ / \mathrm{PJ}$ \\
& 2080 & $60 \%$ & $2170 \$ / \mathrm{kW}$ & $65.3 \$ / \mathrm{kWa}$ & $1.64 \mathrm{M} \$ / \mathrm{PJ}$ \\
\hline
\end{tabular}

\section{Scenarios definition}

The scenarios defined in this work aim to analyse the possible evolution of the global energy system over a very long time horizon and under specific constraints. Two scenarios based on the hypothesis of a moderate growth development have been built:

- Base case scenario: with no $\mathrm{CO}_{2}$ emissions restrictions

- Base 450 ppm scenario: with a limit of $450 \mathrm{ppm}$ in $\mathrm{CO}_{2}$-eq concentrations set by 2100

Besides, a Tax scenario has been created for the sensitivity analysis introducing a price-based policy option different among regions and growing over time. In OECD regions, the $\mathrm{CO}_{2}$ tax rises from $20 \$ / \mathrm{tCO}_{2}$ in 2020 to $50 \$ / \mathrm{tCO}_{2}$ in 2100 . In non OECD regions, taxes vary from $10 \$ / \mathrm{tCO}_{2}$ in 2020 to $25 \$ / \mathrm{tCO}_{2}$ in 2100 .

In the Base and Base 450ppm scenarios, default socioeconomic demand drivers are the result of the GEM-E3 general equilibrium model. A sensitivity analysis has also been performed for an alternative hypothesis of high growth development based on a set of alternative drivers produced by the dynamic version of the general equilibrium model for global trade and production, Gtap model.

\section{Results on electricity production}

In the Base scenario, analyzed in previous Socio-Economic Research on Fusion projects (SERF), coal technologies play a dominant role reaching half of the global power production in 2100 . There is also an important share of fission technologies mainly from 2040 and at the end of the period fission share is $25 \%$ of the total. Wind onshore and hydropower are the main renewable technologies entering the system. All renewable technologies (RES) amount for $16 \%$ of the production in 2100 . There is no participation of CCS technologies in this scenario, and fusion does not enter the electricity system.

The amount of production increases from $290 \mathrm{EJ}$ in the Base scenario to $322 \mathrm{EJ}$ in the Base $450 \mathrm{ppm}$, due to the higher penetration of electric technologies in the sectors of final demand. In this scenario coal fired generation phases out at 2050, and gas becomes negligible from 2070. The gap is filled by fission production and renewable with an increase also for CSP and offshore wind generation; the share of production is $22 \%$ at 2100 for both fission and renewable. CCS (mainly gas fired) enters the solution from 2050, although the contribution to global electricity production is still negligible (almost $1 \%$ in the period 2050-2100). The share of fusion is $36 \%$ of total production in 2100 which shows that fusion does enter the system when strict $\mathrm{CO}_{2}$ emission restrictions are set. 


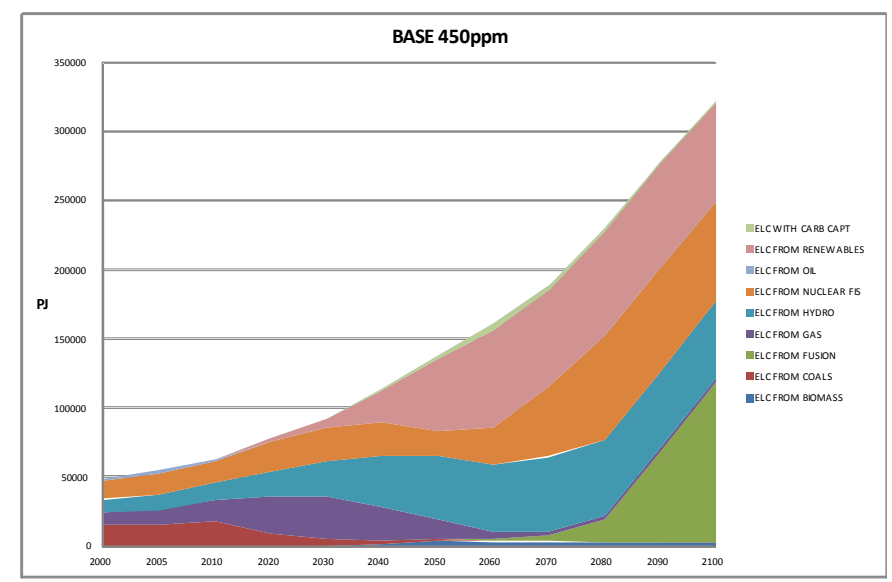

Fig.1. Global electricity generation mix in the Base $450 \mathrm{ppm}$ scenario

A sensitivity analysis on the effect of carbon taxes on the role of fusion has been performed. In the Base Tax scenario, coal still plays a relevant role accounting for $8 \%$ of total electricity production in 2100. Coal becomes a transition technology between 2050 and 2080, when most of Light Water Reactors (LWR) phase out and new base load capacity is needed. Due to the lower levels of the carbon tax, new capacity is installed mainly in Asia (IND and ODA accounts for $2 / 3$ of the installed capacity in 2050). At a global level, after a peak reached in 2070, coal fuelled generation is progressively displaced by nuclear production with fusion and Advanced Breeder Reactor (ABR). Natural Gas fired electricity generation increases considerably in the first part of the century representing a share of about $25 \%$ of electricity production in 2050 when it is widely diffused in all the regions except China. In the second half of the century production declines, partially displaced by renewables and nuclear technologies. The share of hydropower production grows from $18 \%$ in 2000 to $28 \%$ between 2050 and 2070 , and shrinks back to $20 \%$ in 2100 . The maximum potential is reached at the middle of the century in all the regions and no absolute increase is possible in latest periods. Renewable production increases considerably, rising from a negligible share at the beginning of the century up to $23 \%$ in 2100 . The increase is due to onshore wind. Offshore production is a transition option in some regions between 2050 and 2080, while CSP plays a minor role and is used only in Africa, China and India. In the first part of the century nuclear fission represents a share of $20-30 \%$ of total electricity production. Between 2040 and 2060 the share decreases due to the partial replacement of LWR capacity that goes out of production. Between 2040 and 2050 ABR gradually starts to replace LWR confirming the key role of nuclear energy that, at the end of the century, covers a share of $10 \%$ and is diffused in all the regions. Fusion power enters the market since 2050, when basic power plants are installed in India, China, Western Europe, USA, Japan, Mexico and in Other developing Asian countries. The technology represents still a niche option and produces a share of electricity of about $1 \%$ between 2050 and 2070 . The massive contribution of fusion power to global electricity production starts in 2070 when Advanced plants are available and the technology is widespread in all the regions except Central and South America and Middle East. The share of fusion production rises to $20 \%$ in 2090, and to $36 \%$ in 2100 . 


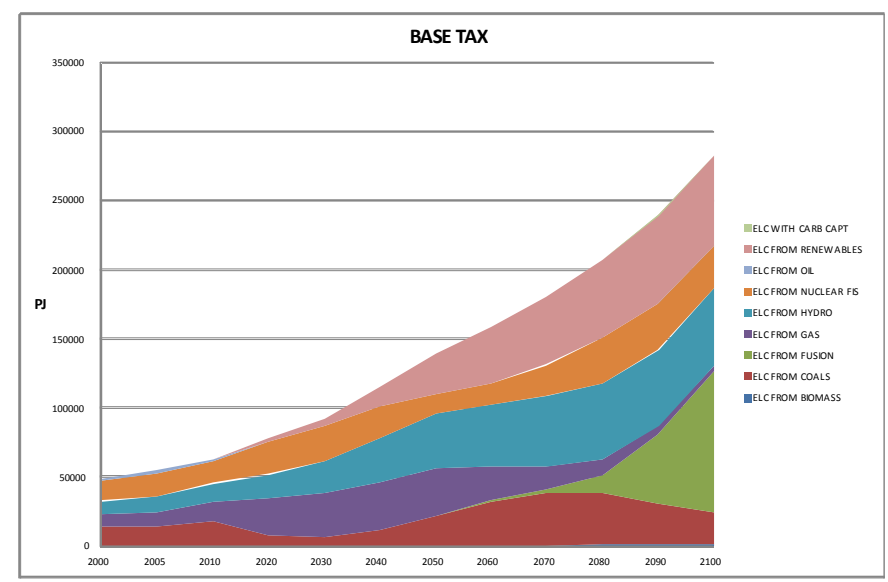

Fig.2. Global electricity generation mix in the Base Tax scenario

Regarding the sensitivity analysis on the electricity demand growth, in 2100 , electricity production, compared to production of the base year, increases by a factor of 8 in the HG Tax scenario and by a factor of 9 in the HG $450 \mathrm{ppm}$ scenario with emission constraints.

Some of the considerations drawn in the description of the Base scenarios still hold for the High Growth case. In particular coal-fired generation plays a relevant role in the HG Tax scenario (particularly in China, India and Other Developing Asian at the middle of the century), reaching a maximum of production in 2070 , and being progressively displaced by nuclear production (fusion and $\mathrm{ABR}$ ) afterwards.

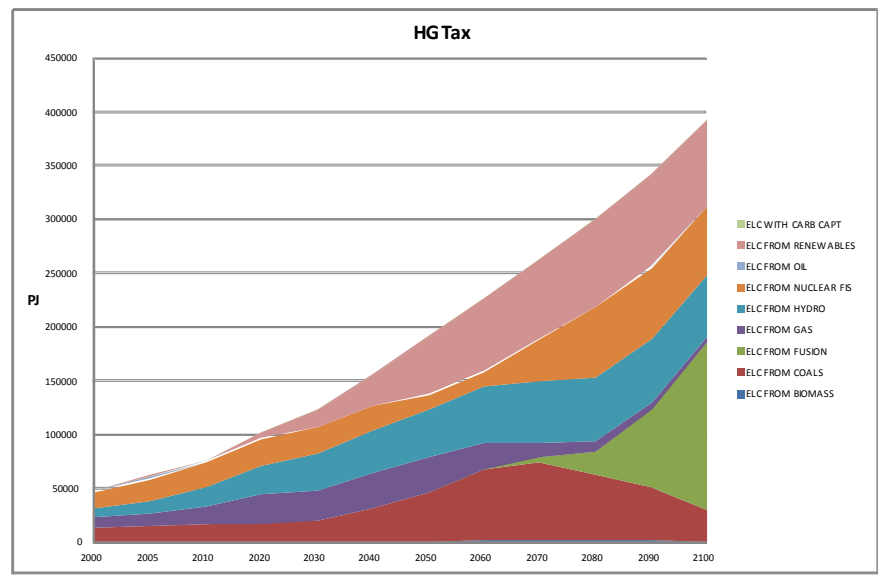

Fig. 3. Global electricity generation mix in the High Growth Tax scenario

In the HG 450 ppm scenario, coal fired generation phases out in 2050. Natural Gas fired electricity generation is relevant and widely diffused in the first part of the century; in the second half of the century production declines, partially displaced by renewables and nuclear technologies. Hydropower production reaches the maximum potential at the middle of the century in all the regions and no absolute increase is possible in latest periods. Fission production is approximately constant until 2060. Fusion and ABR electricity production penetrates massively at the end of the century. The higher level of demand and the stringency of environmental constraints play in favour of these two sources. By 2100 fusion represents almost $37 \%$ of electricity production in the HG scenarios, while the share of fission is $16 \%$ in the HG Tax scenario, and about $28 \%$ in the HG 450 ppm scenario. In both scenarios, renewable production increases considerably, rising from a negligible share at the beginning of the century up to $20 \%$ in 2100 . The absolute amount of 
production is higher than in the Base scenarios. Differently from what has been observed in the Base scenarios, the HG scenarios show a considerable amount of CSP production in the final part of the century in the HG 450 ppm scenario.

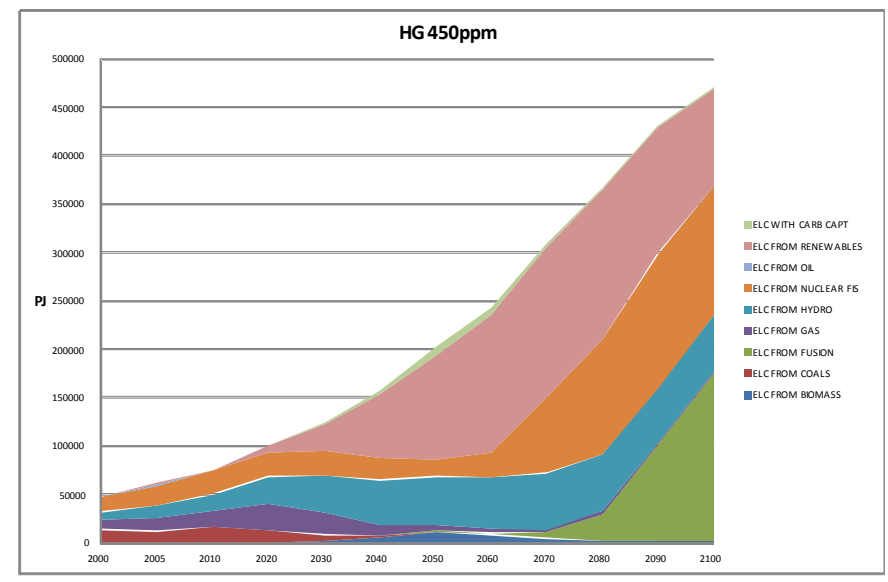

Fig. 4. Global electricity generation mix in the High Growth $450 \mathrm{ppm}$ scenario

\section{Conclusions}

Fusion represents a key technological option for future energy system. The key driver for fusion penetration is a concern for climate change. The adoption of environmental measures, even in the weaker form of a $\mathrm{CO}_{2}$ tax differentiated among regions and with a moderate path of growth, is sufficient to push fusion into the electricity market at the end of the century. Fusion results seem robust against different paths of economic growth. Fusion role is also linked to the tightness of environmental constraints.

Regarding the regional distribution of fusion plants, in the Base $450 \mathrm{ppm}$ scenario, at the beginning fusion power enters the market since 2050, when basic power plants are installed in India, China, Western Europe, USA, South Korea, and other developing Asian countries. However, when Advanced plants are available, the technology spreads in all the regions except Central and South America. With higher demand growths, in the HG 450 ppm scenario, from 2050 basic power plants are installed in all the regions, with less capacity in Central and South America, Mexico and Canada. Then, when Advanced plants are available, the technology spreads in all the regions.

\section{References}

1. R. Loulou, U. Remne, A. Kanudia, A. Lehtila and G. Goldstein. Documentation for the TIMES model. Part I. Introduction (2005)

2. R. Loulou, U. Remne, A. Kanudia, A. Lehtila and G. Goldstein. Documentation for the TIMES model. Part II. Sets and parameters (2005)

3. R. Loulou, U. Remne, A. Kanudia, A. Lehtila and G. Goldstein. Documentation for the TIMES model. Part III. GAMS implementation (2005)

4. D. Van Regemorter. The GEM-E3 model. Model description (2005)

5. E3M Lab. GEM-E3 Model Manual (2010)

6. C. Martini and M. C. Tommasino. General Equilibrium Modelling for energy policies evaluation. The GTAP-E ITA model (2010) 
EPJ Web of Conferences

7. W. Han and D. Ward. Revised assessments of the economics of fusion power. Fusion Engineering and Design 84, 895-898 (2009) 